\title{
COLLABORATION AND COMPETITION POLICY IN A MARKET-BASED HOSPITAL SYSTEM: A CASE STUDY FROM THE NETHERLANDS
}

\author{
Wouter van der Schors, ${ }^{*}$ Ron Kemp, ${ }^{\dagger} \mathcal{E}$ Marco Varkevisser ${ }^{\ddagger}$
}

\begin{abstract}
In the Dutch healthcare system, provider competition is used as a tool to improve efficiency. From a competition policy perspective, little is known about how collaboration among healthcare providers contributes to overall patient welfare, and how a balance is achieved between scale benefits and preventing anticompetitive collusion. This paper examines the ex-post effects of a Dutch case study in which three competing hospitals have collaborated to provide highcomplexity low-volume cancer surgery, an arrangement that tests the limits of permissibility under the Dutch cartel prohibition. Our preliminary empirical research demonstrated only a modest increase in price and travel time for some of the tumour surgeries. Volume analysis showed that the intended centralization of surgical procedures has not been fully realized. Our findings highlight the importance of a comprehensive self-assessment by the collaborating hospitals to ex-ante assess (potential) efficiencies and antitrust risks. Such self-assessments could benefit from research focused on which collaborations are most appropriate to achieve quality gains. For the ex-post assessment by competition authorities following the cartel prohibition, a more thorough insight into the (long-term) changes in hospital prices, profitability, and quality after collaboration is needed.
\end{abstract}

$\mathcal{F E L : ~ I 1 ~ 1 ; ~ I 1 8 ; ~ L 5 0 ~}$

\section{INTRODUCTION}

\section{A. Background}

When hospital competition is used as a tool for improving the efficiency of healthcare (Barros et al., 2016) an interesting challenge arises from the perspective of competition law and economics: i.e. how to deal with the pros \& cons of horizontal consolidation and coordination between (potential)

*PhD Candidate; Erasmus University Rotterdam. Email: vanderschors@eshpm.eur.nl

† Associate Professor/Senior Economist; Erasmus University Rotterdam/Netherlands Authority for Consumer and Markets (ACM). Email: r.g.m.kemp@eshpm.eur.nl. Ron Kemp works for the Netherlands ACM.

\footnotetext{
‡ Full Professor; Erasmus University Rotterdam. Email: varkevisser@eshpm.eur.nl
} 
competitors? ${ }^{1}$ To date, in the literature most attention is being paid to the exante scrutiny and ex-post effects of hospital consolidation. Empirical evidence so far demonstrates that hospital mergers in general do not lower costs and/or improve quality (Cooper et al., 2015; Gaynor et al., 2015; Broers and Kemp, 2017). In a recent study, including 246 acquired hospitals and 1986 control hospitals that did not merge, Beaulieu et al. (2020) find that in the US hospital consolidation did not result in significantly lower readmission or mortality rates while it was associated with a modestly worsening in patient experiences.

Despite their growing importance, collaborations among hospitals have not been subject to the same degree of scrutiny and scientific research compared to mergers. Collaboration can be understood as intermediate or hybrid (network) forms of coordination in which each hospital' autonomy is retained. A prominent example of collaboration between hospitals is a clinical care network (Brown et al., 2016; De Regge et al., 2019). Quality considerations - often operationalised as minimum volume standards-are increasingly incentivizing hospitals to coordinate and/or concentrate their delivery of (complex) treatments in these networks. This is especially true for complex surgical procedures, since volume norms have been introduced that require hospitals to perform a minimum number of surgeries for some treatments (Morche et al., 2018). In general, these norms are prompted by the volume-outcome relationship; i.e. performing a treatment more often results in higher quality. This relationship is confirmed in literature, especially for complex surgical procedures (Gaynor et al., 2005; Burgers et al., 2007; Ho et al., 2007; Rademakers et al., 2012; Gooiker et al., 2014).

In this paper we study collaboration among hospitals within the marketbased Dutch hospital system, where the general prohibition on cartels applies. Therefore, in the Netherlands all arrangements among hospitals are subject to scrutiny under competition law. The increased use of collaborations in hospital markets presents competition authorities with a difficult dilemma (Broers and Kemp, 2017): how to achieve a balance between the potential scale benefits of collaboration while at the same time safeguarding sufficient competition and preventing anti-competitive collusion. Moreover, such cases are highly complex for competition authorities to assess, since a thorough antitrust assessment requires all patient welfare implications to be taken into account, including effects on quality, price and accessibility. In the international literature, Ho et al., (2007) were the first to incorporate both quality, price and travel time effects into a single analysis in order to assess the effects of the centralization of care. However, the existing literature currently lacks both integrated ex-ante and ex-post evaluation studies of horizontal collaboration between hospitals. This case study on collaboration in the Dutch hospital market provides an interesting opportunity in this context.

\footnotetext{
${ }^{1}$ See for example (Baicker and Levy, 2013a).
} 
The case study involves plans drawn up by three hospitals to collaborate intensively through a Comprehensive Cancer Network involving the provision of high-complexity low-volume surgical procedures. The case was informally approved by the Dutch competition authority (ACM) by means of an extensively described informal opinion (See Box 1). This informal opinion, in combination with three datasets containing confidential data on negotiated hospital prices, patient volumes and patient travel times, allowed us to analyse market outcomes shortly after implementation. As price and travel time received less attention in the ex-ante informal opinion, most emphasis will be placed on these potentially patient welfare reducing elements of collaboration. The assessment of the quality effects (efficiencies) will be based on volume analysis, complemented with a brief review of the contemporary literature.

The evaluation of the case study is relevant on three points. First, our study provides insight into the challenges faced by hospitals aiming to improve the quality of care through collaboration, as well as the competition authority who is responsible for preventing anti-competitive collusion. Second, in contrast to the more extensive body of research that is available on hospital mergers, little is known about outcomes of hospital collaboration in terms of price, quality and accessibility. This is an omission, because 'collaboration-without-merging' in networks is likely to play an increasingly important role in international hospital markets under the influence of volume norms, costs containment and a stricter approach by competition authorities towards hospital mergers. Third, we demonstrate the possibilities and (data) restrictions in assessing ex-post patient welfare effects of hospital collaboration.

The paper is structured as follows. After the case description (Box 1), the first section briefly outlines the Dutch healthcare system and the role of competition policy within it. In the second section, we will reflect on the (potential) impact on prices, patient travel times ${ }^{2}$ and quality. Preliminary empirical evidence on price and travel time effects is presented for this purpose. The paper ends with the discussion and conclusion sections. Appendix 1 concerns an extensive case description, while Appendix 2 provides a detailed description of our calculation of the preliminary price effects of the hospital collaboration studied here.

\section{Box 1: Case description}

This study is based on ACM's informal opinion of the collaboration between three hospitals located in or near the city of Utrecht, the fourth largest city in the Netherlands (See Figure 1). An informal opinion is a non-binding informal

2 Please note that the impact on travel time is included here because patients, although generally willing to travel beyond their nearest provider for better care (Aggarwal et al., 2017), prefer hospitals close to their homes. Loosing access to a hospital nearby for a particular service due to centralization may therefore result in lower patient welfare. Additionally, increased travel times for cancer care could reduce treatment uptake for specific patient groups (Parry et al., 2019). 
decision from the ACM on whether a proposed form of collaboration is presumed to be permissible under the Competition Act, with the aim to provide guidance. ${ }^{3}$ The major reason for collaboration mentioned by the hospitals was to meet the minimum volume standards for complex cancer surgery, which are set at twenty procedures per hospital per year, averaged over three years. ${ }^{4}$ In the years 2011 2014, the St. Antonius Hospital missed or only just met the volume standards for esophageal, pancreatic and stomach cancer. The same was true for UMCU and Meander Medical Center (MMC), concerning the volume norms for stomach cancer. Among other changes, under the proposed collaboration St. Antonius hospital would perform surgical procedures for pancreatic cancer and minor liver tumours, UMCU hospital would perform surgical procedures for esophageal cancer and major liver tumours and MMC hospital would perform surgical procedures for stomach cancer and minor liver tumours. ${ }^{5}$ ACM informally approved the proposed collaboration between the three hospitals in December 2015, after which the collaboration came into effect. The ACM assessed the likely improvement in quality of the complex oncological surgery and the retention of complex surgical procedures in the Utrecht region as beneficial for patients. These positive effects of the collaboration were likely to outweigh potential anti-competitive effects such as reduced freedom of choice and potential price increases. The reduction in competition following the collaboration, argued the ACM, would be permissible since the efficiencies would also benefit patients, as is required in the exemption criteria of Article 6 (3) of the Competition Act. Another important point for informal approval was the broad support for the collaboration expressed by both the relevant health insurers in the region and the client councils of the three hospitals. In the realized situation, depending on the geographical market definition, the fascia count in the province of Utrecht decreases from three hospitals to one hospital for each of the complex surgical procedures involved. This implies a substantial increase in market share for the only hospital offering the centralized procedure. The nearest alternative hospitals providing cancer surgery, for instance pancreas procedures, are 35, 44 or $64 \mathrm{~km}$ away by car (as calculated from UMCU). An extensive overview of the claimed efficiencies by the hospitals and potential competition drawbacks can be found in Appendix 1.

\section{B. The Dutch healthcare system}

\section{General overview}

In the Netherlands, the healthcare system has undergone a major reform in the recent decades. Strict government regulation has been replaced by

${ }^{3}$ For the exemption criteria, See Article 6(3) https://wetten.overheid.nl/BWBR0008691/ 2019-01-01.

${ }^{4}$ As shown by the annual BDO Hospital Benchmark (see https://www.bdo.nl/en-gb/industries/hea lthcare/benchmarks), none of the three hospitals was in financial distress.

${ }^{5}$ The Netherlands has 73 hospital organizations, of which 66 are general hospitals and 7 are university hospitals (NVZ, 2018). In 2017, 27 hospitals performed liver resections, 17 hospitals performed stomach or esophageal surgery and 18 performed pancreas surgery (source: minimumkwaliteitsnormen.nl). 


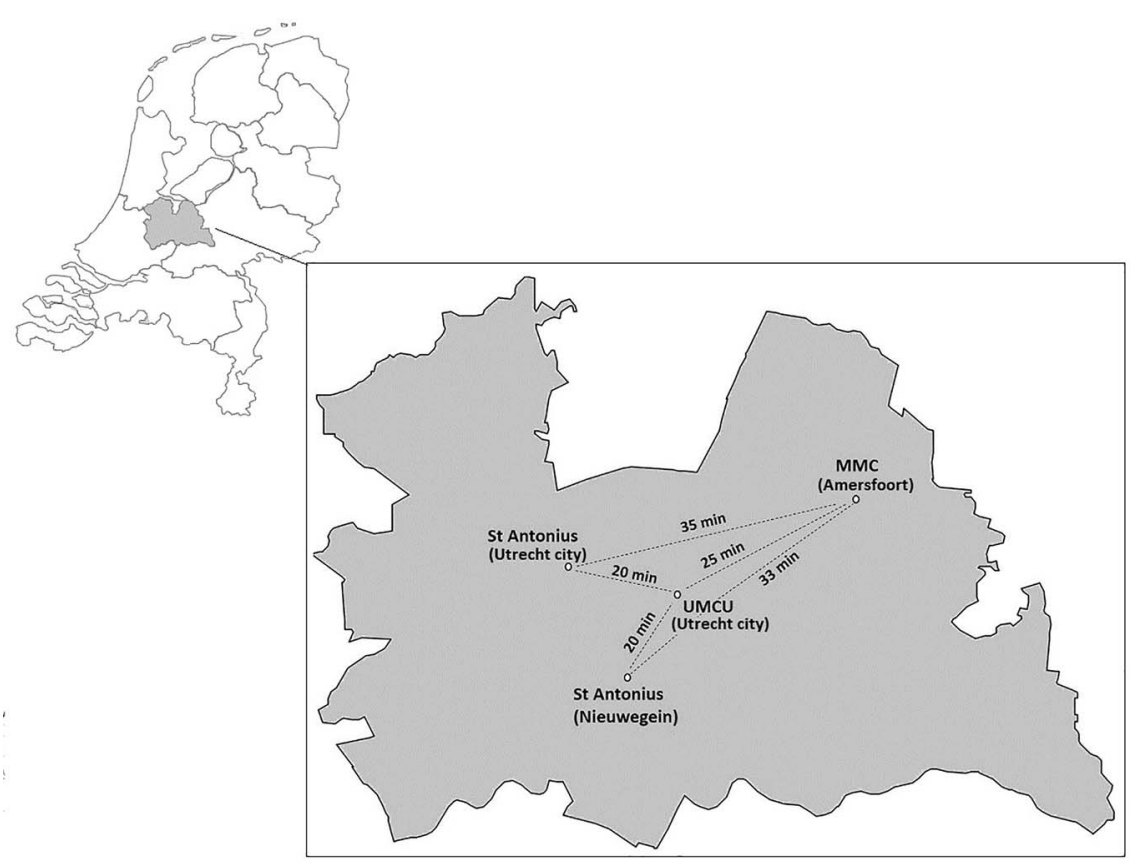

Figure 1. Map of the Netherlands (left) and the province of Utrecht (right), showing the three collaborating hospitals, and travel times by car between their locations.

a system based on the concept of managed competition (Enthoven, 1993; Schut and van de Ven, 2011). A significant date in this process was 1 January 2006, from which point on the Health Insurance Act made private health insurance mandatory for all residents of the Netherlands. A few months later, on 1 October 2006, the Health Care Market Regulation Act came into force, stipulating, among other things, the role of the newly established Dutch Healthcare Authority $(\mathrm{NZa})$ as the regulatory and monitoring body for the healthcare market (Maarse et al., 2016). These market-oriented reforms resulted in a healthcare system organized around three interconnected submarkets in which the health providers, health insurers and patients interact. Health insurers in the Netherlands are expected to act as prudent buyers of healthcare services (Schut and Varkevisser, 2017). To fulfil this role, each health insurer is expected to negotiate with healthcare providers on price, quality and/or volume. Using selective contracting and/or financial incentives for enrolees, health insurers are allowed-and to some extent, expected-to steer patients to those healthcare providers that offer highquality care for a reasonable price (value for money ratio). Reallocating the provision of complex treatments for the sake of quality by means of 
selective contracting can also be seen as one of the tasks of the health insurers.

\section{Stimuli for hospital competition}

All Dutch hospitals are private non-profit foundations facing a legally binding non-distribution constraint which prohibits them from distributing any net earnings. Prior to the major health system reform described above, hospitals were financed by a prospective budgeting system with regulated per diem rates. This system resulted in fairly stable revenue flows for all hospitals. However, since 2006 the hospitals' revenues depend on their contract negotiations with individual health insurers. These negotiations were facilitated by the introduction of a detailed hospital product classification system categorizing each patient into a Diagnosis Treatment Combination (DTC). These DTCs include all hospital activities and services (both inpatient and outpatient) associated with the patient's demand for care, from the initial consultation or examination to the final check-up. Over time, the number of DTCs for which hospitals and insurers are permitted to negotiate prices (labelled as the B-segment) increased from $10 \%$ of hospital revenues at the start, to $20 \%$ in $2008,34 \%$ in 2009 and $70 \%$ in 2012 . For the remainder of the DTCs (labelled as the A-segment), including the most complex ones such as organ transplantations, maximum prices are determined by the NZa. In addition to competing for favourable contracts with health insurers, hospitals also compete directly for patients (Schut and Varkevisser, 2017). ${ }^{6}$ Since the introduction of the new Dutch health care system, patients are encouraged to make an active choice between alternative providers. For example, by the provision of consumer information about hospital quality.

\section{Quality information}

In addition to the supervision on the overall quality by the Health and Youth Care Inspectorate is the public disclosure of quality information considered as an important perquisite for effective hospital competition. Although research suggests the limited role of quality information in selecting healthcare providers by patients (Damman et al., 2009; Faber et al., 2009), steps have been taken in the Netherlands to increase transparency and comparability of these sources. For the surgical procedures for liver, stomach, esophageal, pancreas tumours hospitals are obliged to provide quality data to the National Health Care Institute annually. These indicators include structure, process

${ }^{6}$ Except for the university hospitals, most medical specialists in the Netherlands are self-employed entrepreneurs organized in partnerships. These specialists receive a fixed payment for each DTC. Hence, like the hospitals, these specialists have a financial interest in attracting more patients. 
and outcome indicators, as for instance the number of patients in a year who underwent surgery, standardized mortality rates, waiting times and length of stay. Besides the National Health Care Institute, overarching professional associations as the Dutch Institute for Clinical Auditing (DICA), also divulge hospital quality indicators for oncological care. However, in the Netherlands the development, selection and presentation of these quality indicators are still work in progress, and both the comparability and accessibility are lagging behind (KPMG, 2017). Recent Dutch research on oncological quality indicators highlights that a well-informed hospital selection decision can only be realized with tailored information, preferably outcome indicators, and for a pro-active subset of the population (Salampessy et al., 2019). However, although the publicly available hospital quality ratings are still far from perfect, empirical research indicates that at least to some extent patients - or their GPs offering advice about hospital choice — are sensitive to differences in observed hospital quality (Beukers et al., 2014; Varkevisser et al., 2012).

\section{Antitrust enforcement for collaboration agreements}

In the Netherlands, collaboration agreements between companies are assessed under the Competition Act (Mededingingswet), which came into effect in 1998 and is based on EU competition law. Collaboration-the form of coordination that we focus on in this paper-can be impermissible under the Competition Act if the objective of that collaboration is anti-competitive, or if it leads to anti-competitive effects (Loozen, 2015). The Authority for Consumers \& Markets (ACM) is responsible for applying the Competition Act in all competitive markets, including the market for healthcare. ${ }^{7}$ The supervision of cartel prohibition is relevant when there is an agreement of cooperation between (potentially) competing companies and is defined in article 6(1) of the Competition Act. Article 6(3) provides exemption criteria that allow for agreements to be permitted, even though those agreements would be deemed anti-competitive. ${ }^{8}$ Generally, the ACM will not initiate an investigation of its own accord in cases where healthcare providers can substantiate in a convincing ex-ante self-assessment that the benefits for patients outweigh any anti-competitive effects of collaboration. Furthermore, all relevant stakeholders (e.g. health insurers, patient organizations) must also verify and approve the plan.

${ }^{7}$ For the entire description of the Competition Act (MW), please see: http://wetten.overheid.nl/ BWBR0008691/2016-07-01 (in Dutch).

${ }^{8}$ For the exemption criteria, see Article 6(3): https://wetten.overheid.n1/BWBR0008691/ 2019-01-01 (in Dutch). 


\section{REFLECTION ${ }^{9}$}

\section{A. Potential price effects}

From a welfare perspective, collaborations can lead to inefficiencies due to increased hospital prices. To assess the potential price effects associated with the collaboration studied in this paper, insight into patient volumes at all three hospital locations is required. It can be seen in Table 1 that post-collaboration the centralization has not (yet) been fully materialised for two tumour types. For stomach tumours and pancreas tumours, the percentage of patients that was treated in the hospital where the centralization would take place equalled $70 \%$ and $81 \%$, respectively. Only for esophageal tumours, the centralization has been fully realised; $100 \%$ of the patients underwent surgery in the same hospital. Table 2 shows the indices on which prices were compared with the nationwide average price for the three specific procedures in 2015 (index 100). The method for the calculation of these indices is extensively outlined in Appendix 2. For the indices, we used negotiated prices between hospitals and health insurers as the best available operationalization for any prices effect. The price effect can be subdivided into two sources: in column A and B we assess the potential occurrence of a concentration effect, while in column $\mathrm{C}$ we investigate whether there is any indication of a price effect through the reallocation of care. Column $\mathrm{D}$ was included to simulate the price based on the proposed situation, as Table 1 indicates that the proposed allocation in one hospital has not been fully consummated. ${ }^{10}$ It is important to stress that our analysis should only be regarded as a tentative insight into post-collaboration price effects based on the available data. ${ }^{11}$

To clarify the indices presented in Table 2, we will first discuss the occurrence of a potential concentration effect. That is, the hospitals' potential behavioural change of operating in a now less competitive environment. In column A and column B, we compare the years 2015 and 2017 given a

${ }^{9}$ In this section, we present preliminary empirical evidence for the price and travel-time effects of the collaboration studied in the paper. We do this for the esophageal, stomach and pancreas procedures, and will not present data on liver procedures. For liver tumors, it is important to make the distinction between major and minor tumors in order to assess at which location which patient will be treated. We were not able to make this distinction based on the current data.

${ }^{10}$ It should be noted that we used the situation in which care is provided at one hospital as what would happen without collaboration (counterfactual) instead of 0 hospitals, which refers to the complete disappearance of the tumour surgery in the region. Although the latter scenario was brought forward by the hospitals (Section A of Appendix 1), this counterfactual is highly implausible for three reasons. First, pre-collaboration volumes were sufficiently high enough for insurers to contract at least one hospital, and for some tumours even two hospitals. Second, as selective contracting occurs rarely, not contracting any hospital in the Utrecht region would lead to considerable reputational damage for the health insurers. Third, it is highly implausible to not contract the university hospital as it has an important region function and the nearest other university hospitals are located 42, 64 and $88 \mathrm{~km}$ away.

${ }^{11}$ Due to the limitations of our analysis, which are outlined in the discussion section, conclusions regarding causality between the abuse of market power and price changes could not be drawn. 
Table 1. Percentage of total patient volume centralized in one hospital after collaboration

\begin{tabular}{lcc}
\hline & Realised & Promised \\
\hline Stomach tumours & $70 \%$ & $100 \%$ \\
Pancreas tumours & $81 \%$ & $100 \%$ \\
Esophageal tumours & $100 \%$ & $100 \%$ \\
\hline
\end{tabular}

Table 2. Index prices pre-collaboration and post-collaboration for stomach, pancreas and esophageal ${ }^{12}$ tumours. ${ }^{13}$

$\begin{array}{llll}\text { A } & \text { B } & \text { C } & \text { D } \\ \begin{array}{l}\text { (2015 prices, } \\ 2015 \text { case-mix })\end{array} & \begin{array}{l}\text { (2017 prices, } \\ 2015 \text { case-mix })\end{array} & \begin{array}{l}\text { Realised } \\ (2017 \text { prices. } \\ 2017 \text { case-mix })\end{array} & \begin{array}{l}\text { Consummated } \\ \text { as proposed } \\ (2017 \text { prices, } \\ 2017 \text { case-mix, } \\ \text { procedure fully } \\ \text { centralized in } \\ \text { one hospital) }\end{array} \\ & & & \end{array}$

\begin{tabular}{lcccc}
\hline $\begin{array}{l}\text { Stomach tumours } \\
\text { Nationwide }\end{array}$ & 100 & 105 & 110 & \\
Three hospitals & 103 & 101 & 121 & 123 \\
$\begin{array}{l}\text { Pancreas tumours } \\
\text { Nationwide }\end{array}$ & 100 & 111 & 111 & \\
$\begin{array}{l}\text { Three hospitals } \\
\text { Esophageal tumours }\end{array}$ & 105 & 123 & 104 & 101 \\
$\quad$ Nationwide & 100 & 113 & 111 & \\
Three hospitals & 134 & 137 & 139 & 139 \\
\hline
\end{tabular}

constant case-mix and no re-allocation of care. For stomach procedures, a nationwide price increase of 5 percentage points between 2015 and 2017 is visible (index 105 compared to 100); in the three hospitals concerned in the Utrecht case study, we observe a price decrease of 2 percentage points (index 101 compared to 103). Since the nationwide price increase was larger than the price increase at the three Utrecht hospitals, the three hospitals do not seem to have exercised their market power to demand higher prices. For pancreas procedures, larger price differences are observed. The price increase at the three Utrecht hospitals between 2015 and 2017 (18 percentage points,

${ }^{12}$ Negotiated hospital prices are confidential and competition sensitive, and the exchange of information regarding these prices is forbidden. We therefore made several modifications to the data: 1) we use indices to compare with nationwide prices; 2) every treatment consists of multiple DTC codes; 3) every DTC code consists of multiple prices negotiated by multiple health insurers; 4) the prices are based on averages over the three hospital centres.

${ }^{13}$ In addition to the 'eyeball test'presented in Table 2, we performed a, due to data limitations, simple Difference-in-Differences test on comparing column A to C. No significant differences were found. For confidentiality reasons, no standard deviations from the indices are presented here. 
index 123 compared to 105) was larger than the nationwide price increase (11 percentage points, index 111 compared to 100). This could indicate a small concentration effect. Substantial differences are also observed for esophageal procedures: pre-collaboration, the 2015 prices at the three Utrecht hospitals were higher than the nationwide group (134 compared to 100). However, the price increase at the three hospitals between 2015 and 2017 (3 percentage points, index 137 compared to 134) was lower than the nationwide increase (13 percentage points, index 113 compared to 100). This difference does not indicate the presence of a concentration effect.

Although we find no clear signals for anti-competitive price increases, we know from the literature that higher hospital market shares are generally associated with higher prices (e.g. Gaynor et al., 2015). As the prices are freely negotiable B-segment prices, healthcare providers have the possibility to ask for higher prices. Also for the Netherlands, there are indications that in more competitive regional hospital markets, measured by HHI or weighted market shares (LOCI), ${ }^{14}$ prices are lower (Berden et al., 2019) and quality is higher (Croes et al., 2018). However, most research on market power in relation to price effects applies to consummated hospital mergers (Haas-Wilson and Garmon 2011; ACM, 2017; Lewis and Pflum, 2017). It is not yet clear to what extent through collaborating, as opposed to merging, hospitals can acquire market power in submarkets and the effect this may have on prices.

Furthermore, we assess price differences caused by the allocation of patients. Insight into this separate source of potential price increase is relevant to assess, since the allocation is not coordinated centrally by health insurers or government bodies but is rather determined by the three hospitals involved. Therefore, strategic motives may have had influence on the allocation decision next to medical or patient safety reasons. For instance, hospitals or selfemployed medical specialists may have interest in attracting the procedures with the largest price-cost margins. Although we do not possess price data detailed enough to draw conclusions on the latter, comparing column B and $\mathrm{C}$ might indicate the occurrence of any allocation effect. For stomach tumours, this comparison demonstrates a price increase for the collaborating hospitals of 20 percentage points (index 121 compared to 101), which is higher than the 5 percentage point nationwide price increase. Contrary, for pancreas tumours, the price increases were lower (19 percentage points, index 104 compared to 123) than the nationwide price development, which showed no difference at all. For esophageal tumours, we find a fairly similar price development among the nationwide group and among the three hospitals. However, the price level of the three hospitals for esophageal tumours is much higher than the nationwide price level.

${ }^{14}$ LOCI refers to a competition index developed for differentiated product oligopoly markets with logit demand (Akosa Antwi et al., 2013). 
Since for both columns B and C the 2017 prices are used, differences in the overall price level could be explained by three potential reasons related to allocation of patients. First, post-collaboration, more patients could be treated in a more expensive hospital. This could be an indication of a potential allocation effect. That is, a price increase because procedures were concentrated in a hospital that had higher prices before the collaboration. More patients are then treated for these higher prices, which can result in an upward overall price level after collaboration. This is likely to be the case for the centralization in a university hospital, which generally has higher prices (Douven et al., 2019). Second, it could be the case that the patient population was more complex in 2017 compared to the 2015 patient population (case-mix effect). Third, in addition to a potential case-mix effect, price differences might also be caused by upcoding, implying that a larger share of patients was registered under more complex DTC-codes (Van Herwaarden et al., 2020).

As outlined in Table 1, the centralization has not been fully consummated by the collaborating hospitals. Therefore, we simulated the consummated as proposed situation in column $\mathrm{D}$ to see whether the non-compliance to the assessed plan resulted in any differences in prices. Column $\mathrm{D}$ reflects the situation described in the collaboration plan; i.e. where all treatments would have been centralized in one particular hospital. For stomach tumours, this exercise revealed that the price would then have risen further (123 compared to 121) whereas the price for pancreas tumours would have been lower (101 compared to 104). Presumably, the small increase for stomach tumours is caused by the patients that are still treated in the non-university hospital, which has lower prices. The completion of the proposed centralization in the university hospital would result in slightly higher overall prices. For esophageal tumours, the centralization has been fully realized and therefore a similar index (139) is visible in column C and D.

To summarize, price developments seem to vary for tumour types: the potential price effect of a reduction in competition in comparison to the price effect of other allocation related factors. For stomach tumours, the most substantial price increase is visible, likely caused by the centralization in the university hospital. For pancreas tumours, prices have risen from 2015 to 2017, but this effect has been negated through the centralization in a less expensive hospital. For esophageal tumours, prices in all columns are substantially higher than the nationwide prices. However, the price development does not differ from the nationwide price development. Overall, we do not find a substantial price effect for the three surgical procedures included in the collaboration agreement.

\section{B. Potential travel time effects}

Centralization could potentially increase the travel burden on patients (Middelveldt et al. 2018). Since patients generally dislike travelling for treatment, 
Table 3. Mean travel time in minutes, pre-collaboration

\begin{tabular}{lccc}
\hline & Stomach tumours & Pancreas tumours & Esophageal tumours \\
\hline Nationwide & 24 & 28 & 28 \\
UMCU & 21 & 29 & 25 \\
MMC & 20 & 19 & 15 \\
St. Antonius & 17 & 16 & 21 \\
\hline
\end{tabular}

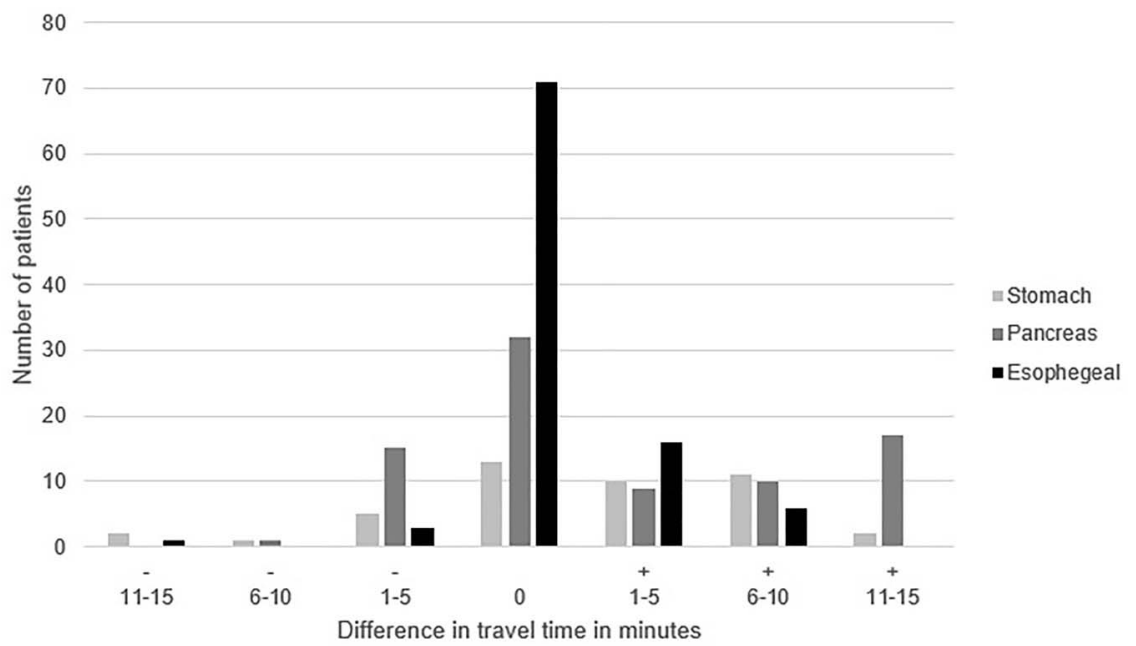

Figure 2. Differences in travel time (minutes) compared to the pre-collaboration situation for the three tumour types. ${ }^{17}$

this could result in significant disutility for some patients, both in terms of increased travel costs and additional travel time (opportunity costs). ${ }^{15}$ Based on patients' places of residence in 2015, we calculated how far patients had to travel for treatment in the pre-collaboration situation (Table 3), and how much their simulated post-collaboration travel time would differ from this (Figure 2). ${ }^{16}$ We refer to 'simulated' post-collaboration travel time because we calculated how far 2015 patients would have had to travel under the new collaboration arrangements, based on actual patient flows and travel times.

${ }^{15}$ See, for example, the comprehensive overview of patient choice literature by Aggarwal et al. (2017).

${ }^{16}$ Using claims data from Vektis, we were able to determine where patients lived and at which hospital they were treated in 2015. The database includes data on $99 \%$ of Dutch citizens collected from all Dutch health insurers. Based on research by Varkevisser et al. (2012), travel times (in minutes) are defined as the fastest route by car from the patient's home to the relevant hospital.

${ }^{17}$ St Antonius hospital has two locations. The complex procedures are performed mainly at the location Nieuwegein. We therefore used this location's postcode for calculating travel times. 
The mean travel time for patients from the three hospitals, as reported in Table 3, is generally slightly lower than the nationwide mean travel time. UMCU reports the highest travel time of the three hospitals for each procedure, which could be explained by the fact that university hospitalswhich serve as centers of excellence-generally serve a wider geographical area than general hospitals. Figure 2 shows the travel time differences per patient for the three tumour types. The large bar at zero represents patients who would have received treatment at the same hospital post-collaboration as pre-collaboration, or for whom the travel time to the new hospital would be unchanged post-collaboration. The negative values on the left tail indicate a decrease in travel time. This implies that these patients bypassed their nearest hospital in the pre-collaboration situation, since their travel time postcollaboration situation would be shorter. The values on the right indicate an increase in travel time. The largest increases in travel time are observed for pancreatic tumours: 17 patients would have travelled 11-15 minutes further. On average, this equates to a relative increase in travel time of 56 per cent for this group, ranging from 15 per cent to 120 per cent extra travelling time. This group thus might suffer a double utility loss; i.e. patients have to travel further, and are obliged to undergo surgery in a less-preferred hospital, or at least not their first choice hospital.

As illustrated in Figure 2, for the majority of the patients the postcollaboration travel times would not have differed substantially from the situation before the collaboration. This is unsurprising, as the three collaborating hospitals are all located within proximity of one another in the same city (in Utrecht) or very nearby (in Amersfoort). These findings provide no clear indication of any increase in patients' travel burden. However, even a small relative increase could be disadvantageous for time-sensitive patients, as well for more vulnerable patient groups such as elderly patients or patients of low socio-economic status (Stitzenberg et al., 2009; Balan, 2017; Versteeg et al., 2018). In general, negative effects on travel times resulting from collaboration are likely to be limited for patients in the Netherlands compared to travel time differences in more sparsely populated countries such as the United States, due to the small size of the Netherlands and the absence of remote areas (Birkmeyer, 2003; Stitzenberg et al., 2009; Mesman et al., 2017). However, given the very densely populated area and three very close hospitals, the travel time differences found in the current Utrecht case may not be entirely representative of potential travel time differences that would result from centralization at hospitals in other, less densely populated areas of the Netherlands.

Other aspects regarding accessibility related to centralization also deserve attention. First, collaboration that aims to centralize care will reduce patients' freedom to make a decision based on their own preferences to some extent, whether these preferences relate to travel time, quality or other hospital attributes (Balan, 2017). This may apply particularly to the patients in Figure 2 
who report a longer pre-collaboration travel time, and who thus initially (i.e. in the pre-collaboration situation) chose a hospital that was further away. In addition to the absolute travel time differences caused by collaboration, it is therefore important to take patients' willingness to travel into account, and this varies between quality-sensitive and time-sensitive patients. In its informal opinion, the ACM assumed that patients were willing to travel further for better care for complex procedures. This argument is partly supported by the relevant academic literature: it has been shown that some patients are more inclined to travel further for higher quality of care, to a certain extent at least (Tanke and Ikkersheim, 2012; Ikkersheim et al., 2013; Gutacker et al., 2016; Middelveldt et al., 2018; Vallejo-Torres et al., 2018).

Second, in the Utrecht case, there is a clear distinction between the locations where diagnosis, surgery and pre- and after care are provided. This implies that the travel time differences shown in Figure 2 may be an underestimation of the actual travel time following the centralization, since patients would need to transfer between locations during the care process. More importantly, this also leads to additional transfer moments which can be unpleasant and cause distress to cancer patients, as well as their relatives (Payne et al., 2000; Vallejo-Torres et al., 2018). The possible move away from a familiar and preferred hospital and surgeon may also be perceived negatively by patients and their relatives, although these implications are more difficult to quantify (Payne et al., 2000; Schwartz et al., 2017; Middelveldt et al., 2018).

\section{Quality}

In the current case, the rationale for the collaboration between the hospitals was to meet the medical professionals' minimum volume standards for rare types of cancer. In the Netherlands, the current threshold for the types of cancer included in the collaboration is set at 20 procedures per year. From this perspective, for some cancer surgeries centralization could be deemed necessary for the hospitals. However, based on our 2017 volume analysis in Table 1, it can be concluded that the centralization has not fully been realised. For stomach and pancreas tumours, also after the start of the collaboration a share of surgical procedures has still been performed in other hospitals than intended. As a result, even post centralization the actual number of surgical procedures in these hospitals is much lower than the minimum volume threshold of 20 procedures per year. This finding contradicts-and even undermines - the quality claims brought forward by the collaboration hospitals. Additionally, it should be noted that while the collaboration purely focuses on volume this itself is a means rather than an end. As the hospitals themselves argued in the informal opinion: "Through centralization and specialization for complex oncological surgery, survival rates and quality of live will improve, due to reduced post-operative complications." In the absence of reliable quality data, it is not yet possible to say whether the collaboration has indeed led 
to higher quality, although the volume-outcome relationship for the involved surgical procedures in the Utrecht is confirmed in the literature (e.g. Gooiker et al., 2014). An inhibiting factor in most international volume-quality studies is that the mechanism underlying the volume-quality relationship is often not explicitly stated (Harrison, 2012; Mesman et al., 2015). In practice, the existence of the volume-outcome relationship can be attributed to a combination of different mechanisms, as for instance (1) the learning effects for surgeons (practice-makes-perfect), (2) the organizational scale size, and (3) a reversed causation by selective referrals; i.e. hospitals or physicians that show better outcomes attract more patients (Gaynor et al., 2005; Luft et al., 1987). Moreover, the occurrence of the volume outcome relationship is highly dependent of contextual factors, which vary according to the procedure in question. In the current case, centralization was also paired with specific attributes that could influence the volume-quality relationship positively or negatively. For instance, pre- and post-operative care is separated from the surgical procedures, surgery is performed by two multidisciplinary teams, and diagnoses are handled at one location. Since the underlying mechanisms and desired quality improvements are unclear, it was ex-ante difficult for the competition authority to assess whether the generally claimed benefits of increased scale would also apply for this case with its specific characteristics. However, ex-post no further research was conducted as well. Neither was any study carried out as to whether collaborations like this one might reduce the incentives for quality competition. A growing body of literature demonstrates the potentially positive effects of hospital competition on quality (Bloom et al., 2015; Escarce et al., 2006; Gaynor et al., 2015), which implies that the benefits of collaboration are (partly) offset by reduced competition on hospital outcomes. $^{18}$

\section{DISCUSSION}

Also in market-based health systems, like in the Netherlands, collaboration between hospitals in clinical care networks is becoming increasingly widespread. This trend is likely to continue due to the influence of both external and internal factors, such as changes in demand, a smaller workforce, stricter volume norms and a stricter approach to mergers on the part of competition authorities (Broers and Kemp, 2017; Glied and Altman, 2017). However, little is known about the total patient welfare effects of collaboration agreements between healthcare providers in competitive markets. From a competition policy perspective, insight into these effects is required in order to enforce antitrust regulations effectively. Uncertainty regarding the conditions

18 The focus of this literature is on the negative ex-post quality effects of reduced competition caused by hospital integration through mergers rather than by collaboration (Gaynor and Town, 2012; Significant, 2016; Vogt and Town, 2006). 
under which collaboration is permissible could encourage mergers between hospitals. This is undesirable because mergers can result in permanent and unfavourable changes in the market structure (Schmid and Varkevisser, 2016).

In this article, we have discussed a case study involving three Dutch hospitals to illustrate three aspects that are considered important in any evaluation of patient welfare: quality, price and travel times. For two of the three tumour types included in the collaboration, our preliminary findings indicate lower prices compared to the nationwide price development. However, for stomach tumours, a price increase is found, although this price difference is small. In absolute terms, the calculation of travel time effects revealed a modest increase in the travel burden for patients. Quality gains resulting from the collaboration were not possible to assess at this stage. However, an analysis of patient volumes revealed that the centralisation - and thus the collaborating hospitals' quality claims - has no (yet) be fully materialised.

\section{A. Limitations}

Our study should be regarded as an initial exploratory investigation in which several limitations apply.

First, in the absence of cost prices or margins, it is questionable whether negotiated prices are sufficiently suitable as an indicator of price effects. These prices are composed of individual DTC prices. Douven et al. (2019) argue that the setting of DTC prices is somewhat arbitrary and serves primarily an instrumental purpose in the annual overall turnover negotiations between hospitals and health insurers, which hampers the validity of DTC prices. In our study, we have focused on three surgical treatments, each consisting of several DTCs. The effect of individual DTC prices may therefore be mitigated because we calculated the average cost per patient. This introduces a (potential) aggregation bias, but for reasons of confidentiality we are not able to disaggregate the price effect. ${ }^{19}$ Second, negotiations between health insurers and health providers are complex and include volume agreements, cross subsidies and joint negotiations for a set of DTCs. For example, hospitals may have agreed with health insurers that higher prices for specific DTCs would be accompanied by treating fewer patients under these more expensive DTCs. This could result in lower overall spending. Finally, our descriptive comparison does not exclude the possibility of confounders that may have influenced price changes. In general, our ex-post study concerns the period just after implementation, which may underestimate or overestimate the actual collaboration effects.

${ }^{19}$ When examining the price effects of a Dutch hospital merger, Roos et al. (2019) indeed find evidence of heterogeneous price effects across health insurers, hospital products and hospital locations. These differences depend on the degree of substitution between hospitals, the relative bargaining ability of hospitals and insurers, and the pre-merger price-cost margins of different products delivered by these hospitals. 


\section{B. Challenges}

Overall, our findings highlight three important challenges for collaborating hospitals as well as competition authorities assessing such arrangements.

First, with regards to the current enforcement method for collaborations, the burden of proof for efficiency claims rests with the healthcare providers concerned. In contrast to merger control, the prohibition on cartels is enforced retrospectively. Our case clearly illustrates the complexity of ex-post assessment, and any ex-ante estimation would thus be even more complex, both for healthcare providers and competition authorities. An effective self-assessment by healthcare providers regarding whether the proposed collaboration complies with competition rules is therefore an essential prerequisite. Healthcare providers should therefore be encouraged to provide insight into the utility and necessity of the proposed collaboration in accordance with the exemption criteria, and efficiency claims should be supported with relevant literature. With respect to quality, the argumentation provided should be required to take a broader perspective than purely focusing on minimum volumes. The mechanism that underlies the (assumed) relationship between quality and volume, as well as the contextual factors that affect this, should also be addressed. This would require more robust substantiation on the part of the applicants, and it is questionable whether all healthcare providers would be sufficiently equipped to demonstrate the net benefits of collaboration in this way. Additionally, the current enforcement method requires competition authorities to have the knowledge and ability to assess applications, and where necessary to refute or expand on the argumentation presented.

Second, for a convincing burden of proof, the self-assessment should ideally be complemented with a scenario analysis to ensure a more comprehensive approach to the best-case and worse-case scenarios. Our ex-post research could be an example of how healthcare providers could utilise their own patient data for ex-ante calculations of the impact of collaboration on travel times in a practical manner. Similarly, the allocation effect could be calculated ex-ante in order to determine the potential implications of concentration at one hospital and could be used in the discussion regarding the extent to which price increases would be justified by quality gains. However, one debate that arises concerns who is responsible for conducting these analyses: the healthcare providers, health insurers or the competition authority? The former (or a trusted consultant/third party) is not legally allowed to share this competition-sensitive information directly, while the latter lacks the capacity and resources to do so for every collaboration agreement.

In addition to the complexity involved in the self-assessment and the related division of tasks, the third challenge is more fundamental and relates to the initiator of collaboration. In the current case, the healthcare providers initiated 
and designed the allocation of the tumour types among the hospitals. However, requesting an exemption on the cartel prohibition would not have been necessary if health insurers had used their selective buying power by means of selective contracting. The role of health insurers in the current case was limited to examining and approving the plan presented by the providers. More proactive intervention by health insurers could result in a shift in emphasis towards value-for-money considerations. This would match the role of prudent buyers of health care that insurers - or other third-party payers-are expected to play in a market-based health system.

\section{Further research}

Further ex-post research is required in order to investigate the patient welfare effects of collaboration and centralization agreements in greater depth. To support both the competition authorities and healthcare providers in their ex-ante substantiation of their claims, future research should provide insight into the effects of cases of collaboration and offer competition authorities the opportunity to steer or enforce in response to indications that anti-cartel regulations have been broken. We recommend that future work includes research questions on whether and how quality benefits are actually realized in the context of collaboration, and whether and which collaborations are the right instruments to achieve the intended quality gains. Finally, further research is required into whether the establishment of collaboration between hospitals is associated with anti-competitive drawbacks. For this purpose, any post-collaboration changes in (disaggregated) prices and included price-cost margins need to be monitored closely, as these provide a more thorough insight into the occurrence of any anti-competitive behaviour.

\section{CONCLUSION}

In this paper, we discussed the potential patient welfare implications of collaboration arrangements between three hospitals providing complex cancer surgery in the Netherlands. Based on the informal opinion issued by the competition authority and additional empirical research, we found only a modest increase in price and travel time for some of the tumour types included in the collaboration. Volume analysis showed that the intended centralization of surgical procedures has not been fully realized. Our findings highlight the importance of a comprehensive self-assessment by the collaborating hospitals to assess efficiencies and risks ex-ante. From the competition policy perspective, a comprehensive self-assessment (e.g. based on the relevant literature) by the collaborating hospitals is required in order to reveal the most important pros \& cons of the aimed collaboration. Such assessments could benefit from research focused on the ex-post evaluation of the quality effects of collaboration. That is, when are the claimed efficiencies most likely 
to occur? For the ex-post assessment on the cartel prohibition by competition authorities, a more thorough insight into the (long-term) changes in hospital prices, profitability, and quality is needed.

\section{Conflict of interest}

Ron Kemp works for the Netherlands Authority for Consumers and Markets (ACM). This paper reflects the personal views of the authors and does not necessarily reflect those of the ACM. This paper is not in any way binding for the Dutch government, in particular for future decisions of the ACM on the topics discussed.

\section{A. APPENDIX}

\section{A.1. Centralization of complex oncological care in the Utrecht region}

Before implementing their plan, the hospitals asked the ACM to assess their argumentation for the collaboration by issuing an informal opinion regarding their plans. An informal opinion is a non-binding informal decision from the ACM on whether a proposed form of coordination is presumed to be permissible under the Competition Act. It is issued with the aim of providing the parties involved with guidance. Generally, informal opinions are issued at the request of the relevant parties and when (1) the proposed arrangements have not yet been implemented and concern a new legal question, (2) when the issue is of economic or societal importance (3) and when enough information has been provided by the parties to form an informal opinion, without the need for the ACM to conduct its own in-depth study.

This collaboration, which was proposed by the hospitals in 2014/2015, concerns three points: (1) the joint establishment of treatment plans for individual patients by physicians through a multidisciplinary meeting; (2) the introduction of a common healthcare protocol and process for different types of tumours and the exchange of expertise; and (3) the centralization of surgical procedures for each form of liver, esophageal, pancreatic and stomach cancer in one or two of the hospitals concerned. Our prime focus in this study is on the centralization of the latter procedures. Under the proposed collaboration, after centralization, St. Antonius hospital would perform surgical procedures for pancreatic cancer and minor liver tumours, UMCU would perform surgical procedures for esophageal cancer and major liver tumours and MMC would perform surgical procedures for stomach cancer and major liver tumours. $^{20}$

${ }^{20}$ The Netherlands has 73 hosptials, of which 66 are general hospitals and 7 are university hospitals (NVZ, 2018). In 2017, 27 hospitals performed liver resections, 17 hospitals performed stomach or esophageal surgery and 18 performed pancreas surgery (source: miniumukwaliteitsnormen.nl). 


\section{A.1.1 The efficiencies claimed by the hospitals}

The major reason for collaboration given by the hospitals was to meet the minimum volume standards for complex cancer surgery. In the Netherlands, these standards are determined by SONCOS, a foundation in which all professional organizations for oncological care in the Netherlands participate. The volume standards for liver, esophageal, pancreatic and stomach cancer surgery are set at twenty procedures per hospital per year, averaged over three years. The three hospitals argued that they would only be able to meet these volume standards if they worked together; otherwise, they feared that highcomplex oncological care may disappear from the region since health insurers would no longer contract the individual hospitals because they would not meet the volume requirements. In the years 2011-2014, the St. Antonius Hospital missed or only just met the volume standards for esophageal, pancreatic and stomach cancer. The same was true for UMCU and MMC, concerning the volume norms for stomach cancer.

The three hospitals argued that patients would benefit from this collaboration because specialization and higher volumes would improve care outcomes, improving survival rates and quality of life and reducing postoperative complications. They also argued that the continued availability of complex cancer care in the Utrecht region would be a further major advantage of the collaboration. The hospitals also emphasized that collaboration on highcomplexity cancer care would not go beyond what was necessary to achieve the volume norms: the centrization of care in one hospital would only apply to the surgical procedures themselves. Pre- and postoperative care would continue to be provided by the hospital of the patient's choice.

\section{A.1.2 Antitrust assessment by the ACM}

In response of the efficiency claims outlined by the hospitals, the ACM's informal opinion considered two potential anti-competitive effects: reduced freedom of choice and the possibility of price increases. The concentration of surgical procedures in one hospital rather than three hospitals reduces absolute freedom of choice. In the status quo situation, patients and health insurers would be able to choose between the three hospitals in the region. In the proposed new situation, however, the hospitals would decide on behalf of the patient where surgery would take place. Additionally, it was possible that relative freedom of choice would be restricted by the proposed arrangements, since the hospitals would aim to standardize the care process for complex oncological care by establishing joint treatment plans. The effect of this approach would be a more harmonized and standardized care process. Hospitals may therefore offer very similar treatment plans, decreasing patient choice regarding aspects such as quality of care. However, the hospitals claimed that 
choice would remain available regarding other aspects of care, such as the level of service for pre- and post-operative care.

Second, the hospitals may be subject to less competitive pressure, reducing the incentives for cost-efficiency and quality. Hospitals could also abuse their market position by negotiating higher prices with health insurers. Finally, the collaboration could result higher costs due to duplication in healthcare processes caused by the potential complexity of providing care at several locations (the location for the surgical procedure may be different from the location of pre- and post-operative care, such as chemotherapy), as well in higher management and coordination costs.

But in spite of these possible anti-competitive aspects of the collaboration, the ACM informally approved the proposed collaboration between the three hospitals in December 2015. Accepting the efficiency claims outlined by the hospitals, the competition authority argued that the positive effects of the collaboration were likely to outweigh the negative effects on competition. The ACM assessed the likely improvement in quality of the complex oncological surgery and the retention of complex surgical procedures in the Utrecht region as beneficial for patients. The reduction in competition following the collaboration, argued the ACM, would be permissible since the efficiencies would also benefit patients, as stated in Article 6 (3) of the Competition Act. Another important point in the approval of the ACM was the broad support for the collaboration expressed by both the relevant health insurers in the region and the client councils of the three hospitals. ${ }^{21}$ For example, the largest and therefore most important health insurer in the region argued that it would continue to have sufficient countervailing purchasing power even after the collaboration.

Following the informal approval by the ACM, the three hospitals went on to found the Regional Academic Cancer Centre Utrecht (RAKU). Two multidisciplinary teams now perform surgical procedures for complex liver, stomach, bile duct and esophageal tumours at UMCU. Pancreas surgery is performed at a location of the St. Antonius hospital, while all three hospitals remain responsible for the minor, less complex liver resections. Note that the actual distribution of surgical procedures thus differs from the initial plan. In the actual situation, MMC only provides minor resections for liver cancer; i.e. stomach procedures are transferred from MMC to UMCU. The reason for the difference between the proposals and the actual situation is that the health insurers consulted as part of the informal opinion suggested centralizing both stomach and esophageal surgeries at one hospital, since this would safeguard quality and patient safety, based on the literature. The hospitals therefore decided to centralize both esophageal and stomach procedures at UMCU.

${ }^{21}$ These parties had insight into the same documents as the plan presented to the ACM. In its assessment, the ACM attaches significant value to the opinions of the health insurers and client councils. 


\section{B. APPENDIX}

\section{A.2. Step-By-Step method for calculation of price effects}

Column A: $\frac{\sum\left(Q_{2015} \times \text { Price }_{2015}\right)}{N(\text { patients })}$

Column B: $\frac{\sum\left(Q_{2015} \times \text { Price }_{2017}\right)}{N(\text { patients })}$

Column C: $\frac{\sum\left(Q_{2017} \times \text { Price }_{2017}\right)}{N(\text { patients })}$

Column D (Stomach/esophegeal): $\frac{\sum\left(Q_{2017} \times \text { Price }_{2017} \mathrm{UMCU}\right)}{N(\text { patients })}$

(Pancreas): $\frac{\sum\left(Q_{2017} \times \text { Price }_{2017} \text { St Antonius }\right)}{N(\text { patients })}$

1) We determined which DTC codes belonged to each surgical procedure, based on the public DTC website of the Dutch Healthcare Authority (NZa).

2) We made use of the 2015 case- and treatment mix to calculate the mean pre- collaboration prices. This means that we took the population who underwent surgery in 2015 as the starting point for the calculation of 2015 and 2017 prices, to allow for comparability between the years (Column A and B)

3) We then acquired the negotiated hospital-health insurer prices for each DTC code. We did this for the negotiated price in 2015 and 2017. Since hospitals negotiate the prices per DTC annually with their insurer, the price per DTC was likely to be different for 2015 compared to 2017.

4) The total expenditure per hospital was calculated by summing the number of DTCs performed in that hospital multiplied by the price per DTC: $\sum\left(Q_{D T C} \times P_{D T C}\right)$.

5) The mean pre-collaboration price per patient per hospital is calculated by dividing the total expenditure per hospital per tumour (as calculated under point 3$)$ by the number of treated patients: $\frac{\sum\left(Q_{D T C} \times P_{D T C}\right)}{N(\text { patients })}$. We did this for 2015 and as a hypothetical benchmark also for 2017 , based on the 2015 case- and treatment mix

6) Based on mean prices for the three individual hospitals, we calculated one mean price for the three hospitals, weighted for the number of patients in each hospital.

7) We also conducted steps 1-5 for the nationwide control group. The nationwide group refers to the mean price for patients treated by all hospitals in the Netherlands that performed the procedure. The three collaborating hospitals in our case were excluded from the nationwide group.

8) We also conducted steps 1-5 for column C, making use of 2017 casemix and 2017 prices.

9) To calculate the post-collaboration price based on the consummated as proposed centralization (Column D), we made use of the 2017 case 
and treatment mix. We made use of 2017 prices for the hospital at which the procedure would have been centralized. For stomach and esophageal cancer, this was the UMCU, for pancreatic cancer, this was the St. Antonius Hospital. The total expenditure was calculated by summing the number of DTCs performed at the three hospitals, multiplied by the price per DTC at the centralized hospital (UMCU or St. Antonius Hospital): $\sum\left(Q_{D T C} \times P_{D T C}\right.$ centralized $)$. The mean price was computed by dividing the total expenditure by the total number of patients.

10) Since the negotiated prices are confidential and competition-sensitive, we report the price differences in Table 2 utilizing indices based on the 2015 nationwide prices as the index (100). Therefore, indices above 100 indicate a higher price, indices below 100 indicate a lower price.

\section{REFERENCES}

ACM 2017. Price and volume effects of hospital mergers https://www.acm.nl/sites/de fault/files/documents/2018-01/report-price-and-volume-effects-of-hospital-me rgers.pdf.

Aggarwal, A., Lewis, D., Mason, M., Sullivan, R., van der Meulen, J. (2017), 'Patient mobility for elective secondary health Care Services in Response to patient choice policies: A systematic review', Medical Care Research and Review. SAGE Publications Inc., 74(4): 379-403. http://journals.sagepub.com/ doi/10.1177/1077558716654631 [13 February 2020].

Akosa Antwi, Y., Gaynor, M., Vogt, W.B. 2013. A Competition Index for Differentiated Products Oligopoly with an Application to Hospital Markets *.

Baicker, K., Levy, H. 2013. Coordination versus competition in health care reform, New England fournal of Medicine, 369(9): 789-91. http://www.nejm.org/doi/10.1056/NE JMp1306268.

Balan, D.J. 2017. Merger-Specificity of Quality and Cost Efficiencies in Hospital Merger Cases, Competition Policy International.

Barros, P.P., Brouwer, W.B.F., Thomson, S., Varkevisser, M. 2016. 'Competition among health care providers: Helpful or harmful?', European fournal of Health Economics, Springer Verlag, 17(3): 229-33.

Beaulieu, N.D., Dafny, L.S., Landon, B.E., Dalton, J.B., Kuye, I., McWilliams, J.M. (2020), 'Changes in quality of care after hospital mergers and acquisitions', New England Fournal of Medicine. Massachussetts Medical Society, 382(1): 51-59. http:// www.nejm.org/doi/10.1056/NEJMsa1901383 [13 February 2020].

Berden, C., Croes, R., Kemp, R., Mikkers, M., Van der Noll, R., Shestalova, V., Svitak, J. (2019), 'Hospital competition in the Netherlands: An empirical investigation'. https://papers.ssrn.com/sol3/papers.cfm?abstract_id=3383564\#\%23 [5 February 2020].

Beukers, P.D.C., Kemp, R.G.M., Varkevisser, M. (2014), 'Patient hospital choice for hip replacement: Empirical evidence from the Netherlands', European fournal of 
Health Economics. Springer Verlag, 15(9): 927-936. http://www.ncbi.nlm.nih.gov/pu bmed/24158316 [13 February 2020].

Birkmeyer, J.D. 2003. Regionalization of high-risk surgery and implications for patient travel times, $\mathscr{f} A M A, \mathbf{2 9 0}(20): 2703$. http://jama.jamanetwork.com/article.aspx? doi=10.1001/jama.290.20.2703.

Bloom, N., Propper, C., Seiler, S., Van Reenen, J. 2015. The impact of competition on management quality: Evidence from public hospitals, The Review of Economic Studies, 82(2): 457-89. https://academic.oup.com/restud/article-lookup/doi/10.1093/re stud/rdu045.

Broers, B., Kemp, R. 2017. Dutch hospital mergers: No evidence for improvement of healthcare quality, Competition Policy International, 1: 60-7.

Brown, B.B., Patel, C., Mcinnes, E., Mays, N., Young, J., Haines, M. 2016. The effectiveness of clinical networks in improving quality of care and patient outcomes : A systematic review of quantitative and qualitative studies, BMC Health Services Research. BMC Health Services Research, 1-16. http://dx.doi.org/10.1186/ s12913-016-1615-z.

Burgers, J.S., Wittenberg, J., Kallewaard, M., van Croonenborg, J.J., van Barneveld, T.A., van Everdingen, J.J.E. 2007. Relationship between volume and quality of care for surgical interventions; results of a literature review, Nederlands tijdschrift voor geneeskunde, 151(38): 2105-10 http://www.ncbi.nlm.nih.gov/pubmed/17948827.

Cooper, Z., Craig, S., Gaynor, M., Van Reenen, J. (2015), The Price Ain't Right? Hospital Prices and Health Spending on the Privately Insured. Cambridge, MA. http://www.nbe r.org/papers/w21815.pdf.

Croes, R.R., Krabbe-Alkemade, Y.J.F.M., Mikkers, M.C. 2018. Competition and quality indicators in the health care sector: Empirical evidence from the Dutch hospital sector, The European Fournal of Health Economics, 19(1): 5-19. http://link. springer.com/10.1007/s10198-016-0862-6.

Damman, O. C., Hendriks, M., Rademakers, J., Delnoij, D. M., Groenewegen, P. P. (2009), 'How do healthcare consumers process and evaluate comparative healthcare information? A qualitative study using cognitive interviews', BMC Public Health, 9(1): 423. https://bmcpublichealth.biomedcentral.com/article s/10.1186/1471-2458-9-423 [5 February 2020].

De Regge, M., De Pourcq, K., Van de Voorde, C., Van den Heede, K., Gemmel, P., Eeckloo, K. 2019. The introduction of hospital networks in Belgium: The path from policy statements to the 2019 legislation, Health Policy, 123(7): 601-5. https:// linkinghub.elsevier.com/retrieve/pii/S0168851019301277.

Douven, R., Burger, M., Schut, F. 2019. 'Does managed competition constrain hospitals' contract prices? Evidence from the Netherlands', Health Economics, Policy and Law, 1-14. https:/www.cambridge.org/core/product/identifier/ S1744133119000215/type/journal_article.

Enthoven, A.C. 1993. The history and principles of managed competition, Health Affairs, 12(suppl 1): 24-48. http://www.healthaffairs.org/doi/10.1377/hlthaff.12.Su ppl_1.24.

Escarce, J.J., Jain, A.K., Rogowski, J. 2006. Hospital competition, managed care, and mortality after hospitalization for medical conditions: Evidence from three states, Medical Care Research and Review, 63(6_suppl): 112S-40S. http://journals.sagepu b.com/doi/10.1177/1077558706293839. 
Faber, M., Bosch, M., Wollersheim, H., Leatherman, S., Grol, R. 2009. Public reporting in health care: How do consumers use quality-of-care information? A systematic review, Medical Care, 1-8.

Gaynor, M., Ho, K., Town, R.J. 2015. The industrial Organization of Health-Care Markets, Fournal of Economic Literature, 53(2): 235-84. http://pubs.aeaweb.org/ doi/10.1257/jel.53.2.235.

Gaynor, M., Seider, H., Vogt, W.B. 2005. The volume-outcome effect, scale economies, and learning-by-doing, American Economic Review, 95(2): 243-7. http://pubs. aeawe b.org/doi/10.1257/000282805774670329.

Gaynor, M., Town, R. 2012. The impact of hospital consolidation -Update, Robert Wood Fohnson Foundation Policy Brief, 9 (June): 1-8. http://www.rwjf.org/content/da $\mathrm{m} /$ farm/reports/issue_briefs/2012/rwif73261.

Glied, S.A., Altman, S.H. 2017. Beyond antitrust: Health care and health insurance market trends and the future of competition, Health Affairs, 36(9): 1572-7. http:// www.healthaffairs.org/doi/10.1377/hlthaff.2017.0555.

Gooiker, G.A., Lemmens, V.E.P.P., Besselink, M.G., Busch, O.R., Bonsing, B.A., Molenaar, I.Q., Tollenaar, R.A.E.M., de Hingh, I.H.J.T., Wouters, M.W.J.M. 2014. Impact of centralization of pancreatic cancer surgery on resection rates and survival, British fournal of Surgery, 101(8): 1000-5. http://doi.wiley.com/10.1002/ bjs. 9468 .

Gutacker, N., Siciliani, L., Moscelli, G., Gravelle, H. 2016. Choice of hospital: Which type of quality matters? Fournal of Health Economics, 50: 230-46. https://linkinghu b.elsevier.com/retrieve/pii/S0167629616301370.

Haas-Wilson, D., Garmon, C. 2011. Hospital mergers and competitive effects: Two retrospective analyses, International fournal of the Economics of Business, 18(1): 17-32. http://www.tandfonline.com/doi/abs/10.1080/13571516.2011.542952.

Harrison, A. 2012. Assessing the relationship between volume and outcome in hospital services: Implications for service centralization, Health Services Management Research, 25(1): 1-6. http://journals.sagepub.com/doi/10.1258/hsmr.2011.011027.

Ho, V., Town, R.J., Heslin, M.J. 2007. Regionalization versus competition in complex cancer surgery, Health Economics, Policy and Law, 2(01): 51. http://www.journals. cambridge.org/abstract_S1744133106006256.

Ikkersheim, D., Tanke, M., van Schooten, G., de Bresser, N., Fleuren, H. 2013. Modeling hospital infrastructure by optimizing quality, accessibility and efficiency via a mixed integer programming model, BMC Health Services Research, 13(1): 220. http://bmchealthservres.biomedcentral.com/articles/10.1186/1472-6963-13-220.

KPMG 2017. Goed, beter, best. https://assets.kpmg/content/dam/kpmg/nl/pdf/2017/se ctor/gezondheidszorg/goed-beter-best.pdf. [5 February 2020].

Lewis, M.S., Pflum, K.E. 2017. Hospital systems and bargaining power: Evidence from out-of-market acquisitions, The RAND fournal of Economics, 48(3): 579-610. http://doi.wiley.com/10.1111/1756-2171.12186.

Loozen, E.M.H. 2015. Public healthcare interests require strict competition enforcement, Health Policy, 119(7): 882-8. https://linkinghub.elsevier.com/retrieve/pii/ S0168851015000391.

Luft, H.S., Hunt, S.S., Maerki, S.C. 1987. The volume-outcome relationship: Practicemakes-perfect or selective-referral patterns? Health services research, 22(2): 157-82 https://www.ncbi.nlm.nih.gov/pubmed/3112042. 
Maarse, H., Jeurissen, P., Ruwaard, D. 2016. Results of the market-oriented reform in the Netherlands: A review, Health Economics, Policy and Law, 11(02): 161-78. http://www.journals.cambridge.org/abstract_S1744133115000353.

Mesman, R., Faber, M.J., Westert, G.P., Berden, B.J.J.M. 2017. Dutch surgeons' views on the volume-outcome mechanism in surgery: A qualitative interview study, International fournal for Quality in Health Care, 29(6): 797-802. http://academic. oup.com/intqhc/article/29/6/797/4079833.

Mesman, R., Westert, G.P., Berden, B.J.M.M., Faber, M.J. 2015. Why do high-volume hospitals achieve better outcomes? A systematic review about intermediate factors in volume-outcome relationships, Health Policy, 119(8): 1055-67. https://linkinghu b.elsevier.com/retrieve/pii/S0168851015001001.

Middelveldt, I., Regts, G., Van der Zwaag, E. 2018. De ontwikkeling van oncologienetwerken in Nederland, Groningen.

Morche, J., Renner, D., Pietsch, B., Kaiser, L., Brönneke, J., Gruber, S., Matthias, K. 2018. International comparison of minimum volume standards for hospitals, Health Policy, 122(11): 1165-76. https://inkinghub.elsevier.com/retrieve/pii/ S016885101830424X.

NVZ 2018. Brancherapport algemene ziekenhuizen 2018, Utrecht.

Parry, M. G., Sujenthiran, A., Cowling, T. E., Nossiter, J., Cathcart, P., Clarke, N. W., Payne, H., Aggarwal, A., Meulen, J. (2019), 'Impact of cancer service centralisation on the radical treatment of men with high-risk and locally advanced prostate cancer: A national cross-sectional analysis in England', International fournal of Cancer. Wiley-Liss Inc., 145(1): 40-48. https://onlinelibrary.wiley.com/ doi/abs/10.1002/ijc.32068 [13 February 2020].

Payne, S., Jarrett, N., Jeffs, D. 2000. The impact of travel on cancer patients' experiences of treatment: A literature review, European fournal of Cancer Care, 9(4): 197-203. http://doi.wiley.com/10.1046/j.1365-2354.2000.00225.x.

Rademakers, J., Zuiderent-Jerak, T., Kool, T. (2012), 'Inleiding: de relatie tussen volume en kwaliteit van zorg. Tijd voor een brede benadering.' https:/www.narcis.nl/publi cation/RecordID/publicat:4753 [28 November 2018].

Roos, A. F., Croes, R. R., Shestalova, V., Varkevisser, M., \& Schut, F. T. (2019). 'Price effects of a hospital merger: Heterogeneity across health insurers, hospital products, and hospital locations', Health Economics, 28(9): 1130-45.

Salampessy, B. H., Bijlsma, W. R., van der Hijden, E., Koolman, X., Portrait, F. R. M. (2019), 'On selecting quality indicators: Preferences of patients with breast and colon cancers regarding hospital quality indicators', BMF Quality $\mathcal{E}$ Safety, bmjqs-2019-009818. http://qualitysafety.bmj.com/lookup/doi/10.1136/ bmiqs-2019-009818 [16 December 2019].

Schmid, A., Varkevisser, M. 2016. Hospital merger control in Germany, the Netherlands and England: Experiences and challenges, Health Policy, 120(1): 16-25. https://linkinghub.elsevier.com/retrieve/pii/S016885101500278X.

Schut, F.T., van de Ven, W.P.M.M. 2011. 'Effects of purchaser competition in the Dutch health system: Is the glass half full or half empty?', Health Economics, Policy and Law, 6(01): 109-23. http://www.journals.cambridge.org/abstra ct_S1744133110000381.

Schut, F.T., Varkevisser, M. 2017. 'Competition policy for health care provision in the Netherlands', Health Policy, Elsevier Ireland Ltd, 121(2): 126-33. 
Schwartz, D.M., Fong, Z.V., Warshaw, A.L., Zinner, M.J., Chang, D.C. 2017. The hidden consequences of the volume pledge, Annals of Surgery, 265(2): 273-4. http://insights.ovid.com/crossref?an=00000658-201702000-00008.

Significant 2016. Ziekenhuisfusies en kwaliteit van zorg: Onderzoek naar de effecten van ziekenhuisfusies op de kwaliteit van zorg, Barneveld.

Stitzenberg, K.B., Sigurdson, E.R., Egleston, B.L., Starkey, R.B., Meropol, N.J. 2009. Centralization of cancer surgery: Implications for patient access to optimal care, fournal of Clinical Oncology, 27(28): 4671-8. http://ascopubs.org/doi/10.1200/ JCO.2008.20.1715.

Tanke, M.A.C., Ikkersheim, D.E. 2012. A new approach to the tradeoff between quality and accessibility of health care, Health Policy, 105(2-3): 282-7. https://linkinghub.e lsevier.com/retrieve/pii/S0168851012000620.

Vallejo-Torres, L., Melnychuk, M., Vindrola-Padros, C., Aitchison, M., Clarke, C.S., Fulop, N.J. et al. 2018. Discrete-choice experiment to analyse preferences for centralizing specialist cancer surgery services, British fournal of Surgery, 105(5): 587-96. http://doi.wiley.com/10.1002/bjs.10761.

Van Herwaarden, S., Wallenburg, I., Messelink, J., Bal, R. 2020. Opening the black box of diagnosis-related groups (DRGs): Unpacking the technical remuneration structure of the Dutch DRG system. Health Economics, Policy and Law. Cambridge University Press.

Varkevisser, M., van der Geest, S.A., Schut, F.T. 2012. Do patients choose hospitals with high quality ratings? Empirical evidence from the market for angioplasty in the Netherlands, fournal of Health Economics, 31(2): 371-8. https://linkinghub.else vier.com/retrieve/pii/S0167629612000082.

Versteeg, S.E., Ho, V.K.Y., Siesling, S., Varkevisser, M. 2018. Centralisation of cancer surgery and the impact on patients' travel burden, Health Policy, 122(9): 1028-34. https://linkinghub.elsevier.com/retrieve/pii/S0168851018302173.

Vogt, W.B., Town, R. 2006. How has hospital consolidation affected the price and quality of hospital care? Synthesis. 